\title{
Impacts of Perceived Role Demands on Psychological Well-Being and the Moderating Effect of Gender: the Case of Public Service Professionals in Sri Lanka
}

\author{
Rajagopalasingam, V. ${ }^{1}$, Fernando, R. L. S. ${ }^{2}, \&$ Ramanayake, U. B. ${ }^{3}$ \\ ${ }^{1} \mathrm{PhD}$ Candidate, University of Sri Jayewardenepura, Sri Lanka \\ ${ }^{2}$ Senior Professor, University of Sri Jayewardenepura, Sri Lanka \\ ${ }^{3}$ Visiting Senior Lecturer, University of Sri Jayewardenepura, Sri Lanka \\ Correspondence: Rajagopalasingam, V., University of Sri Jayewardenepura, Sri Lanka.
}

Received: May 21, 2020

Accepted: June 18, 2020

Online Published: June 23, 2020

doi:10.5539/ibr.v13n7p156

URL: https://doi.org/10.5539/ibr.v13n7p156

\begin{abstract}
The purpose of this study was to examine the level of psychological well-being among professionals and to determine the individual and combined impacts of perceived work, family and social role demands on psychological well-being and also to analyze the moderating effect of gender between perceived role demands and psychological well-being relationships. This research was designed based on both quantitative and cross sectional in nature. The data for the present study were collected through questionnaire survey and stratified random sampling techniques from a total of 386 Sri Lankan professionals of Chartered Engineers, Medical Officers and Accountants representing in the public service organizations in Sri Lanka. Multiple regression using SPSS 23 and Structural Equation Modeling in Amos 21 were used to analyze data. The results elucidated that professionals possess moderate level of psychological well-being. There is significant negative causal impacts of perceived work, family and social demands on psychological well-being. The degree of combined effects of perceived role demands were significantly impacts on Psychological Well-being. Furthermore, gender has significant moderation effect between perceived role demands and psychological well-being relationship. The limitation of this study was that of cross-sectional and all measures were self-reported that common method variance may influence the findings. This study is significance to professionals, employees, family members, human resource managers, medical officers, psychologist, policy makers and researchers to address the needs of employees regarding psychological well-being issues. This is one of the few studies to provide empirical evidence of social demands on psychological well-being in a collectivist cultural context of Sri Lanka. The value of this paper contributes to the understanding of individual and combined impacts of perceived work, family and social role demands on psychological well-being. Further studies using longitudinal design would be useful in establishing the temporal order of relationship among variables.
\end{abstract}

Keywords: role demands, psychological well-being, accountants, gender, Sri Lanka

\section{Introduction to the Study}

Sri Lanka is an Island situated in the Indian Ocean with a total population of 21 million. In the recent years, globally well-being research has been growing extensively across disciplines. Well-being is defined as the state of having no anxiety, uneasiness, depression and other psychological disorders in individual's life (Ryff, 1995). Work, family and social domains are important and inter-connected to most professionals. Performing of multiple role impacts their individuals' life significantly. Role demands are defined as structural or psychological claims associated with role requirements, expectations and norms to which individuals must respond or adopt by exerting physical or mental effort (Voydanoff, 2004a). Psychological well-being is a broader concept and one of the most important mindful aspects based on individual experiences that determine the success of an individual in their work and personal life. Aristotle claimed that true happiness is found by leading a virtues life and doing what is worth doing. Huppert (2009) defined Psychological well-being is about lives going well and it is the combination of feeling good and functioning effectively. According to Epidemiological report of Ministry of Health, Sri Lanka (2017), the estimated total depression and anxiety disorder cases in Sri Lanka are $4.1 \%$ and $3.4 \%$ respectively of total population. According to Register General, Sri Lanka (2019), suicide mortality rate in 
Sri Lanka for year 2018 was14.6 per 100,000 and according to WHO, a suicide rate that exceeds 13 per 100,000 is high. The World Health Organization estimates that $7 \%$ of Sri Lankans live with a disability including mental disorders (WHO, 2011b). These evidences show that Sri Lanka is need of a response in policy at institutional and community level. Work, family and social domains are most important and inter-connected to most professionals and performing of multiple role system may impact their individuals' life significantly. Furthermore, professionals often encounter challenges and problems with managing multiple roles that may hinder their psychological well-being which is a prerequisite for their effective and efficient functions of their true domains. It is believed that a successful career with personal and family life is indeed challenging due to the fact that the higher the position, the more time, energy and attention that professionals must invest in work and personal life roles. Changing demographic structure of the workforce in Sri Lanka has been the primary force behind the increased focus on multiple role demand issues. Wright et al., (2007) claimed that performance was highest when employees reported high score on psychological well-being. This shows the importance of psychological well-being among professional. The relationship between gender and Psychological well-being has been examined in this study to see whether men and women differs with psychological well-being and to determine the influence of gender of this study. Thus, this paper examines the level of perceived psychological well-being among the professionals and to determine the individual and combined impacts of perceived work, family and social role demands on psychological well-being and to analyze the moderating effect of gender among the professionals employed in the public service of Sri Lanka.

\section{Literature Review and Hypotheses}

\subsection{Psychological Well-being}

There are two philosophical paradigm approaches concerning the well-being in the literature named as hedonic approach and eudaimonic approach. Aristippus, a Greek philosopher equating well-being with hedonic pleasure or happiness and taught that the goal of life is to experience the maximum amount of pleasure. Aristotle was the founder father of the concept eudaimonia and its meaning is good spirit and claimed that realizing human potential is the ultimate goal of life. According to Ryff's (1989), Psychological Well-being refers to the extent to which people feel that they have meaningful control over their life and their activities and developed six factor model of psychological well-being that is globally validated and consist of self- acceptance, autonomy, environmental mastery, personal growth, positive relation with others and purpose in life. Different authors define and conceptualize psychological well-being differently as shown in Table 1.

Table 1. Psychological Well-being conceptualizations

\begin{tabular}{|c|c|}
\hline Source & Definition \\
\hline Bradburn, 1969 & $\begin{array}{l}\text { Proposed a two-dimensional model of psychological well-being, distinguishing between positive } \\
\text { and negative affect. }\end{array}$ \\
\hline $\begin{array}{l}\text { Gechman } \\
\text { \&Wiener, } 1975\end{array}$ & Efficiency of psychological functioning of an individual. \\
\hline Sekaran, 1985 & Overall effectiveness of an individual's psychological functioning. \\
\hline Ryff,1989 & Optimal psychological functioning and experience. \\
\hline $\begin{array}{l}\text { Helson \& Srivastava, } \\
2001\end{array}$ & $\begin{array}{l}\text { Psychological well-being develops through a combination of emotional regulation, personality } \\
\text { characteristics and identity and life experience. }\end{array}$ \\
\hline Edwards, 2005 & Psychological well-being refers to positive mental health. \\
\hline Deci and Ryan,2008 & $\begin{array}{l}\text { Refers to living life in a full and deeply satisfying manner and is concerned with living well or } \\
\text { actualizing one's human potentials and the state of optimal efficiency. }\end{array}$ \\
\hline Huppert,2009 & $\begin{array}{l}\text { Psychological well-being is about lives going well. It is the combination of feeling good and } \\
\text { functioning effectively. }\end{array}$ \\
\hline $\begin{array}{l}\text { Robertson, Cooper, \& } \\
\text { Cooper, } 2010\end{array}$ & $\begin{array}{l}\text { Degree to which employees experience positive emotions at work and the extent to which they } \\
\text { experience meaning and purpose in their work. }\end{array}$ \\
\hline Stamp et al., 2015 & $\begin{array}{l}\text { A combination of positive circumstances in all spectrums of life such as contentment, both } \\
\text { physically and spiritually and optimal function. }\end{array}$ \\
\hline $\begin{array}{l}\text { Udhayakumar \& } \\
\text { Illango, } 2018\end{array}$ & Psychological well-being refers to how individuals control their life and activities \\
\hline $\begin{array}{l}\text { Working definition, } \\
2020\end{array}$ & $\begin{array}{l}\text { The extent to which an individual feels positive psychological functioning effectively while } \\
\text { perceive positive emotions satisfactorily by optimizing human potentials. }\end{array}$ \\
\hline
\end{tabular}

The World Health Organization defines mental health as "not merely the absence of mental health problems but as a state of well-being in which every individual realizes his or her own potential, can cope with the normal stresses of life, can work productively and fruitfully, and is able to make a contribution to her or his 
community"(WHO,2014). Moreover, WHO definition elucidates that mental health as a continuum and at one end is mental disorders of ill-being and the other positive end is well-being of psychological well-being.

A paradigm shift is noted in defining psychological well-being by blending the combination of hedonic and eudomonic views. Ryan and Deci (2001) claimed that Psychological well-being has two facets of eudaimonia and hedonic pleasure and defined it as optimal psychological functioning and experience. Further, studies on gender differences in psychological well-being have yielded contradictory findings (Ryff \& Singer, 1998; Roothman et al., 2003). The present review identified, summarized and evaluated the existing major land mark research on psychological well-being.This findings underscores the need to study further on the moderating effect of gender on psychological well-being by the current authors.

\subsection{Perceived Work, Family and Social Role Demands}

Demerouti, Bakker, and Nachreiner (2001) defined work demand as physical, social, or organizational aspect of a job that require sustained physical or mental effort and are therefore associated with certain physiological and psychological costs. Parasuraman et al. (1992) identified that major role demands at work are namely role overload, role conflict and role ambiguity. In the work domain, long work hours and week end schedules have been most frequently studied variable in the literature. Perceived Work demand must be subjectively felt and experienced by the employees for it to influence.

Boyar et al. (2007) defined family demand as a global perception of the level and intensity of responsibility within the family domain. Perceived family demands that are originating in terms of obligation, commitment and responsibilities for household chores, caring for children and eldercare at home are taken into account and is an individual's perception by feels and experience.

Present study has realized a gap in literature regarding perceived social demands that may influence the ability of professionals to fulfill their work and personal life responsibilities. Voydanoff (2004b) claimed that these may include a range of structural and psychological demands located in the community. The working definition of perceived social role demand is the extent to which an individual feels and experiences the burdens of unsafe neighborhood, poor community integration, inadequate social cohesion, increasing friend-based demands and difficulty in participation of professional membership with respect to obligations and commitments beyond work, family and self domains.

\subsection{Gender}

Gender is an important topic that has been extensively reviewed within the literature. Gender refers to the roles and responsibilities of men and women that are created in our societies. Sex describes the biological differences between men and women, which are universal and determined at birth. Men and women prioritize work and family roles differently. Women have more barriers in their jobs than the men (Lyness and Thompson, 2000).

\subsection{The Relationship between Role Demands, Gender and Psychological Well-being}

Thompson (2006) claimed that role over load or heavy job demands lead to work pressure that affect employees physical health as well as psychological well-being. Studies on gender differences in psychological well-being have yielded contradictory findings (Ryff \& Singer, 1998; Roothman et al., 2003 Furthermore, Ryff, (1995) claimed that there were significant gender differences in psychological well-being. In view of these past studies where results indicate contrasting findings on the difference between the psychological well-being aspects and gender.

\subsection{Objectives of the Study}

The objectives of this current study were to examine the level of perceived psychological well-being and to determine the degree of combined and individual impacts of work, family and social role demands on psychological well-being and to analyses the moderating effects of gender between perceived role demands and psychological well-being relationship among the professionals employed in the public service of Sri Lanka.

\subsection{Theoretical Model}

On the basis of the literature review, the following model has been proposed for the study. 


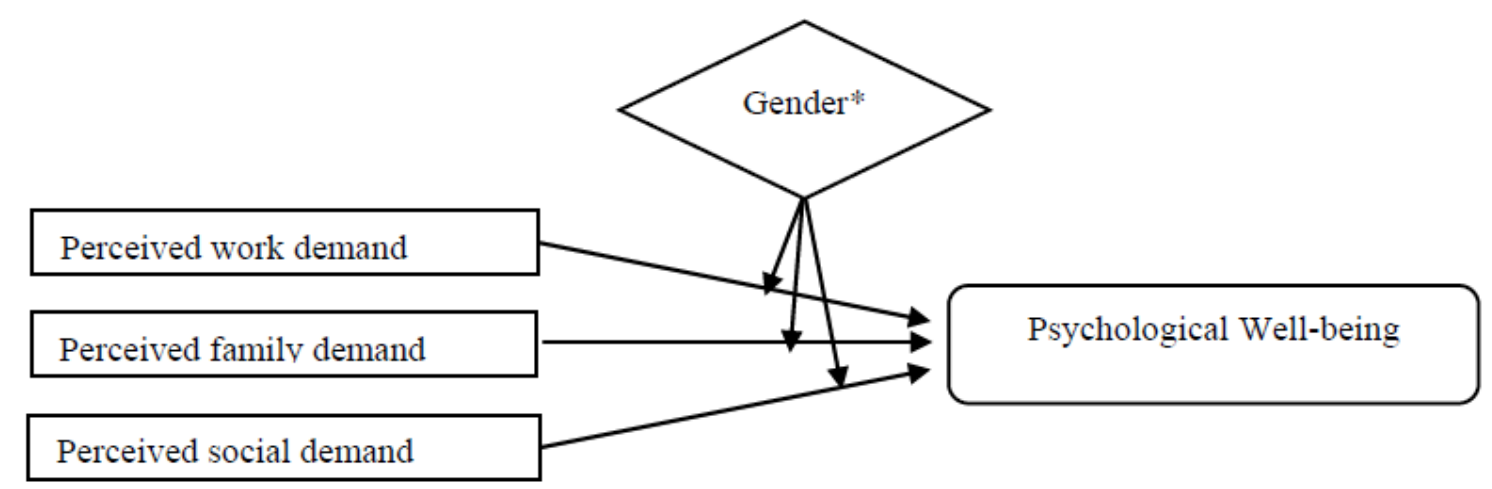

\section{Independent Variable (Predictor Variable)}

*Moderating variable
Dependent Variable

(Criterion Variable)

Figure 1. Conceptual Model with Psychological Well-Being, perceived work, family and social demands

\subsection{Theoretical Lens behind the Model - Role Scarcity Hypothesis Theory}

Role scarcity hypothesis theory has been proposed to explain the effects of multiple roles on Psychological well-being. Role scarcity hypothesis, proposes that increased numbers of roles lead to overload and strain, which can translate into negative effects on physical and psychological well-being (Goode, 1960; Marks, 1977).

\subsection{Hypotheses}

From the literature review, Thompson (2006) claimed that role over load or heavy job demands lead to work pressure that affect employees physical health as well as psychological well-being. A study of examining the relationship between gender and psychological well-being was conducted by Khanbani et al. (2014) and the results showed that there was significant difference between men and women in some of the aspects of psychological well-being. Based on the conceptual model, the literature review and the finding of the above researchers, the following hypotheses were postulated.

H1a: Perceived Work role demands have a significant and negative impact on Professionals' Psychological Well-being.

H1b: Perceived Family role demands have a significant and negative impact on Professionals' Psychological Well-being.

H1c: Perceived Social role demands have a significant and negative impact on Professionals' Psychological Well-being.

H1d: The degree of combined impacts of work role demands, family role demands and social role demands have jointly and significantly impact on Psychological Well-being.

H2a: Perceived Work role demands correlate negatively and significantly to Psychological Well-being.

H2b: Perceived Family role demands correlate negatively and significantly to Psychological Well-being.

H2c: Perceived Social role demands correlate negatively and significantly to Psychological Well-being.

H3a: Gender has a moderating effect on the relationship between work role demands and Psychological Well-being relationship.

H3b: Gender has a moderating effect on the relationship between family role demands and Psychological Well-being relationship.

H3c: Gender has a moderating effect on the relationship between social role demands and Psychological Well-being relationship.

\subsection{Research Gaps}

1) From the literature review, it reveals that the impacts of perceived social demands on psychological well-being has not been empirically tested in a collectivist cultural context of Sri Lanka. 
2) There is few studies to provide empirical evidence of work, family and social role demands on psychological well-being with moderating effects of gender in the context of public service in Sri Lanka using the techniques of Structural Equation Modelling.

3) The value of this paper contributes to the understanding of individual and combined impacts of perceived work, family and social role demands on psychological well-being relationships.

\section{Research Methodology}

\subsection{Research Design}

The current research is explanatory in nature with cross sectional survey. Quantitative data collection approach has been used. Self-reported structured questionnaires were used to measure the constructs. To meet the research objectives, a structural equation model was developed.

\subsection{Population and Sample}

The population of this research study were twenty four thousand professionals $(24,000)$ of Chartered Engineers, Medical Officers and Accountants employed in the public service organizations in Sri Lanka. Sekaran (2003) claimed that a population of 10,000 or more, a researcher would probably consider a sample of 384 . According to Yamane's formula, Sample size $\mathrm{n}=\mathrm{N} / 1+\mathrm{N}(\mathrm{e})^{2}$ where $\mathrm{N}=$ Total population, $\mathrm{e}=$ Margin of error $(0.05), \mathrm{n}=$ $24000 / 1+24000(0.05)^{2}=393$

Hence, sample size for this study was taken as 386 using stratified simple random sampling techniques.

\subsection{Procedures}

Before starting the actual research study, a pilot study was conducted among 35 professionals of Medical officers, Chartered Engineers and Accountants employed in the public sector organizations in Sri Lanka using simple random sampling techniques to assess the internal consistency of the scales. Later, primary data was collected through the use of a written structured questionnaire that was hand delivered and posted by postal mail to randomly selected professionals of Chartered Engineers, Medical Officers and Accountants employed in the public service organizations in Sri Lanka. Each questionnaire was prefaced by a paragraph explaining objectives of the survey. Data collection was taken place during the period of May 2018 to August 2018. A total of 920 questionnaires were distributed to professionals using stratified simple random sampling techniques and 407 were returned and the response rate is $44.24 \%$. Among them, the questionnaires which contained missing data were deleted, resulting in a total of 386 responses was used for empirical analysis.

\subsection{Measures}

The criterion variable used in this study is Psychological Well-Being and predictors are perceived work, family and social role demands. The Questionnaires were divided into three sections, Part A contained questions regarding Demographic Details of respondents, Part B contained 18 items of Psychological Well- Being Scales and Part $\mathrm{C}$ contained 13 items of perceived role demand scales.

\subsubsection{Psychological Well-being Measures}

In this study, Ryff's (1989) Psychological Well-Being short scale and Positive Emotions sub scale developed and validated by current authors were used as shown in Table 2. Ryff's (1989) Psychological Well-Being short scale is one of the most popular and validated scale to measure psychological well-being globally. The original Questionnaires developed by Ryff (1989) is divided in to six sub scales namely Positive Relations with Others (PR), Meaning \& Purpose in Life (MP), Self- Acceptance (SA), Environmental Mastery (ENM), Personal Growth (PG) and Autonomy (AU). For the Sri Lankan context, autonomy subscale was omitted due to the fact that in a collectivist culture, autonomy is not dominant and Positive Emotions subscale has been added by authors. Each sub scale consist of three items using a five point Likert Scale ranging from (1) strongly disagree to (5) strongly agree. Psychological Well-Being scale altogether contained 18 items. 
Table 2. Psychological Well-being measures with sub-scales

\begin{tabular}{lll}
\hline \multicolumn{1}{c}{ Construct } & Indicator & \multicolumn{1}{c}{ Item description } \\
\hline Positive & PE1 & 1. I am feeling happy about myself. \\
Emotion & PE2 & 2. In many ways, I feel very positive towards myself. \\
& PE3 & 3. My daily life has been filled with things that interest me. \\
\hline Positive & PR1 & 4. People would describe me as a giving person, willing to share my time with others. \\
Relations with & PR2 & 5.* Maintaining close relationships has been difficult and frustrating for me. \\
Others & PR3 & 6. I have experienced many warm and trusting relationships with others. \\
\hline Meaning \& & MP1 & 7. Some people wander aimlessly through life, but I am not one of them. \\
Purpose in Life & MP2 & 8. I live life one day at a time and don't really think about the future. \\
& MP3 & 9.* I sometimes feel as if I've done all there is to do in life. \\
\hline Self- & SA1 & 10. I like most aspects of my personality. \\
Acceptance & SA2 & 11.* In many ways, I feel disappointed about my achievements in life. \\
& SA3 & 12. When I look at the story of my life, I am pleased with how things have turned out. \\
\hline Environmental & ENM1 & 13. I am quite good at managing the many responsibilities of my daily life. \\
Mastery & ENM2 & 14. In general, I feel I am in charge of the situation in which I live. \\
& ENM3 & 15. The demands of everyday life often get me down. \\
\hline Personal Growth & PG1 & 16. I think it is important to have new experiences that challenge how you think about \\
& PG2 & yourself and the world. \\
& PG3 & 17. For me, life has been a continuous process of learning, changing and growth. \\
&
\end{tabular}

Sources: Ryff's (1995) and current Authors. * Reverse items

\subsubsection{Perceived Work, Family and Social Role Demands Measures}

Perceived work role demands (PWD) scale was measured using four items developed by Boyar et al. (2007). Perceived family role demands (PFD) scale was measured using three items developed by Boyar et al. (2007) and one item was developed and validated by authors and this item is "I am facing burden on eldercare responsibilities to my family member". Perceived social role demands (PSD) scale was measured using five items developed and validated by current authors and all of these items were anchored using a five point Likert Scale ranging from (1) strongly disagree to (5) strongly agree. These measures are given in Table 3.

Table 3. Perceived Work, Family and Social role demands measures

\begin{tabular}{ccl}
\hline Construct & Indicator & \multicolumn{1}{c}{ Item description } \\
\hline Perceived Work & WD1 & 1. My job requires all of my attention. \\
role demands & WD2 & 2. I am given a lot of work to do. \\
(PWD) & WD3 & 3. My work requires a lot from me. \\
& WD4 & 4. I feel like I have a lot of work demand. \\
\hline Perceived & FD1 & 1. I have to work hard on family-related activities. \\
Family role & FD2 & 2. I have lot responsibility in my family. \\
demands (PFD) & FD3 & 3. I feel like I have a lot of family demand. \\
& FD4 & 4. I am facing burden on eldercare responsibilities to my family member \\
\hline Perceived Social & SD1 & 1. My neighborhood is safe and convenience to me. \\
role demands & SD2 & 2. I feel absence of community integrations around my locality. \\
(PSD) & SD3 & 3. My friends very often make too many demands on me. \\
& SD4 & 4. I cannot make any sense the way my society is going on. \\
& SD5 & 5. My current community based organizational membership is burden to me.
\end{tabular}

Sources: Boyar et al. (2007) and current Authors.

\subsection{Data Analysis}

In this research study, the data collected from research instruments were numerically scored and quantified. Descriptive analysis was conducted using SPSS 23 to calculate the mean, frequency and the standard deviation to assess the level of Psychological Well-being of professionals. Confirmatory Factor analysis (CFA) employing AMOS 21 was used to examine the measurement of latent constructs for unidimensionality, validity and reliability. Stepwise Regression analysis using SPSS 23 was applied to find the combined effects of predictors on psychological well-being. Data were also analyzed using Structural Equation Modelling approach with Amos 21 to test the proposed theoretical model fit and to find the causal individual effects of perceived role demands on Psychological Well-Being. The Multi-Group CFA method in Amos 21 was utilized for testing the moderation 
effect of gender between perceived role demands and Psychological Well-being relationships.

\section{Analysis and Results}

\subsection{Demographic Characteristics of Participants}

In terms of demographic analysis, out of the 386 respondents, $279(72.3 \%)$ were male and $107(27.7 \%)$ were female and 199 (51.6\%) were Sinhalese, 126 (32.6\%) were Sri Lankan Tamils, 55 (14.3\%) were Sri Lankan Muslims and $06(1.5 \%)$ were Indian Tamils. Besides, 155 (40.2\%) respondents were medical officers, 126 (32.6\%) were Chartered Engineers, and 105 (27.2\%) were Accountants. The majority of the respondent's age group was $36-50(41.7 \%)$, followed by age group of 51-61(36.3\%) and lowest age group is $22-35(22 \%)$. In addition, majority of the participants were married $334(86.6 \%), 41(10.6 \%)$ had never been married category, 2 $(0.5 \%)$ were divorced, $2(0.5 \%)$ were separated and $7(1.8 \%)$ were widowed. Majority of the respondents were Bachelor's degree holders 210 (54.4\%). On tenure, most of the respondents had been 15 years -20 years $(25.4 \%)$ category while of least tenure category was 20 years and above (11.4\%).

\subsection{Measurement Model}

The measurement model included four latent variables called as work role demands, family role demands, social role demands and psychological well-being with 31 observed variables. The results of measurement model are given in Figure 2. The results for the measurement model indicates the Goodness of Fit Index (GFI) was 0.872, Normed Fit Index (NFI) was 0.907. Similarly, the Root Mean Square Error of Approximation (RMSEA) yields a good fit of 0.052 and Root Mean Square Residual (RMR) is 0.08.Further, Comparative Fit Index (CFI) was 0.95, Tucker- Lewis Index (TLI) was 0.945 and CMIN/DF value of 2.045 which is within the threshold value of less than 3.0. This measurement model fit indices satisfy the requirements in accordance with threshold values from Zainudeen, (2014).

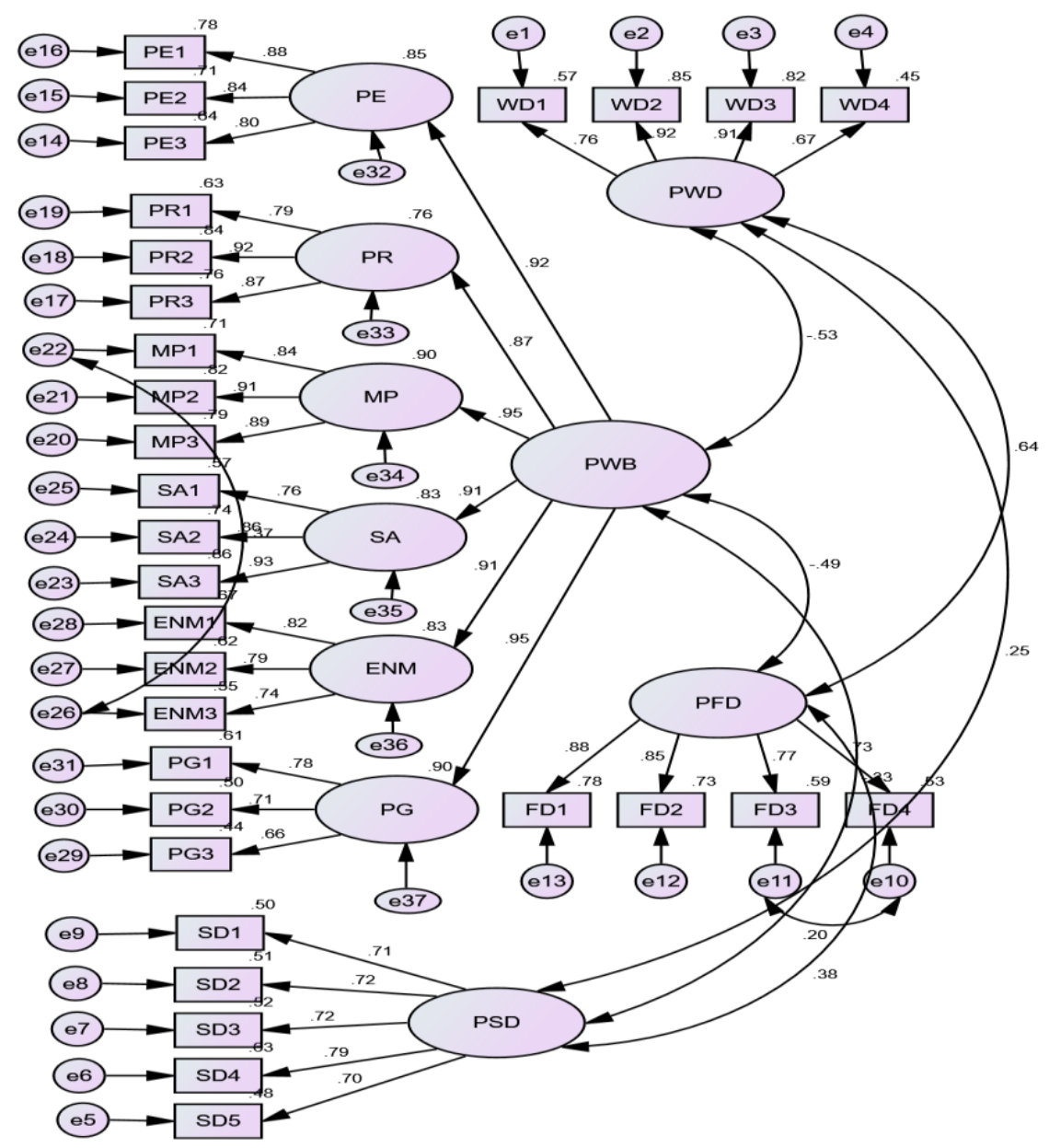

Figure 2. Measurement model of perceived work, family \& social role demands and psychological well-being 


\subsection{Reliability Analysis of Measurement Constructs}

The internal consistency reliability of the measured variables were analyzed using IBM SPSS statistics 23 for Cronbach's Alpha values $(\alpha)$. The reliability values for all measured variables ranged from 0.848 to 0.962 and all values were within threshold values. The threshold of Cronbach's Alpha value should be more than .7 (Nunnally, 1978). Cronbach's Alpha values for Psychological Well-being scale was 0.943, perceived work role demands was 0.888 , perceived family role demands was 0.886 and perceived social role demands was 0.848 and all are within acceptable thresh hold values. Composite Reliability (CR) for all variables were also calculated. The Composite Reliability indicates the reliability and internal consistency of a latent constructs ranged from 0.850 to 0.971 . The cut off value of composite reliability was 0.6 (Fornell \& Larker, 1981). These reliability information are shown in Table 4. Hence, it was concluded that measurement properties for each variable was reliable.

\subsection{Convergent Validity of Measurement Constructs}

Hair et al., (2014) suggested that an item is significant if its factor loading is greater than 0.50. Convergent validity was established both using standardized loadings and Average Variance Extracted (AVE). If an item loads significantly <.5 (Field, 2009) on the factor, it is ensure the convergent validity is prevalent. The Confirmatory Factor Analysis (CFA) showed in the measurement model as per the Figure 1 that each item loading is greater than 0.6 and calculated Average Variance Extracted values are greater than 0.5 as per Table 4 and AVE ranged from 0.531 to 0.847 . AVE $>0.5$ (Fornell \& Larker, 1981) is required for every construct for ensuring the convergent validity. Thus convergent validity has been assured for the measurement variables.

Table 4. Factor Loading, Cronbach's Alpha Reliability Coefficient, Average Variance Extracted and Composite Reliability of Constructs

\begin{tabular}{|c|c|c|c|c|c|c|}
\hline Variable & $\overline{\text { Items }}$ & $\begin{array}{l}\text { Factor } \\
\text { Loading } \\
\end{array}$ & $\begin{array}{ll}\text { Cronbach's Alpha if } \\
\text { Item deleted }\end{array}$ & $\begin{array}{l}\text { Cronbach's } \\
\text { Alpha }(\alpha)\end{array}$ & $\overline{\mathrm{AVE}}$ & $\overline{\mathrm{CR}}$ \\
\hline Psychological & $\overline{\mathrm{PE}}$ & 0.92 & .939 & .943 & 0.847 & 0.971 \\
\hline \multirow[t]{5}{*}{ Well-being } & PR & 0.87 & .940 & & & \\
\hline & MP & 0.95 & .934 & & & \\
\hline & SA & 0.91 & .929 & & & \\
\hline & ENM & 0.91 & .936 & & & \\
\hline & PG & 0.95 & .941 & & & \\
\hline \multirow{4}{*}{$\begin{array}{l}\text { Perceived work role } \\
\text { demands }\end{array}$} & WD1 & 0.76 & .859 & 0.888 & 0.675 & 0.891 \\
\hline & WD2 & 0.92 & .828 & & & \\
\hline & WD3 & 0.91 & .836 & & & \\
\hline & WD4 & 0.67 & .894 & & & \\
\hline \multirow{4}{*}{$\begin{array}{l}\text { Perceived family } \\
\text { role demands }\end{array}$} & FD1 & 0.88 & .833 & 0.886 & 0.657 & 0.884 \\
\hline & FD2 & 0.85 & .851 & & & \\
\hline & FD3 & 0.77 & .859 & & & \\
\hline & FD4 & 0.73 & .871 & & & \\
\hline \multirow{5}{*}{$\begin{array}{l}\text { Perceived social role } \\
\text { demands }\end{array}$} & SD1 & 0.71 & .818 & 0.848 & 0.531 & 0.850 \\
\hline & SD2 & 0.72 & .818 & & & \\
\hline & SD3 & 0.72 & .818 & & & \\
\hline & SD4 & 0.79 & .802 & & & \\
\hline & SD5 & 0.70 & .825 & & & \\
\hline
\end{tabular}

\subsection{Discriminant Validity of Measurement Constructs}

Discriminant validity test was conducted using correlation matrix with square root of the average variance matrix as shown in Table 5. This shows that square root of the average variance extracted for each construct (diagonals) was greater than the inter construct correlations and thereby the required discriminant validity has been established.

Table 5. Discriminant validity test of measurement constructs

\begin{tabular}{lcccc}
\hline Variables & PWB & PWD & PFD & PSD \\
\hline 1.PWB & $\mathbf{. 9 2 0}$ & & & \\
2.PWD & -.457 & $\mathbf{. 8 2 2}$ & & \\
3.PFD & -.492 & .588 & $\mathbf{. 8 1 1}$ & $\mathbf{. 7 2 9}$ \\
4.PSD & -.340 & .210 & .392 & \\
\hline
\end{tabular}


Diagonals represents square root of average variance extracted while off diagonals represents correlations.

**. Correlation is significant at the 0.01 level (2-tailed). PWB- Psychological Well-being,

PWD- Perceived work role demands, PFD- Perceived family role demands, PSD- Perceived social role demands

Since these measurements comply with the recommended threshold values, it is concluded that measurement scales have proper discriminant validity.

\subsection{Descriptive Statistical Analysis}

Descriptive analysis was performed to find out the mean, standard deviation and correlations among all study variables. In this research study, the researchers define three categories of level of Psychological well-being based on the mean value namely (a) Low Psychological well-being Score < 2.61 (Mean - 0.5 S.D.) (b) Moderate Psychological well-being Score between 2.61 (Mean - 0.5 S. D.) and 3.66 (Mean + 0.5 S.D.) (c) High Psychological well-being Score >3.66 (Mean + 0.5 S.D.) in terms of level approach based on five point likert scale. The method used to split the psychological well-being (PWB) is based on the levels approach which has several advantages. PWB levels can be measured at any time and level approach is more efficient and greater generalizability. Further, level changes are not occurred frequently and level approach is best evidence to support organizational- level interventions for combating poor PWB. The analysis findings revealed that overall level of psychological well-being was in the moderate category $(\mathrm{M}=3.13, \mathrm{SD}=1.05)$. The findings also indicated moderate score category of all the dimensions of Positive Emotions $(\mathrm{M}=3.15, \mathrm{SD}=1.27)$, Positive Relations with Others $(\mathrm{M}=3.33, \mathrm{SD}=1.26)$, Meaning \& Purpose in Life $(\mathrm{M}=3.11, \mathrm{SD}=1.33)$, Self- Acceptance $(\mathrm{M}=3.22$, $\mathrm{SD}=1.21)$ and Environmental Mastery $(\mathrm{M}=3.07, \mathrm{SD}=1.07)$ and Personal Growth $(\mathrm{M}=2.89, \mathrm{SD}=1.01)$. These results are presented in Table 6 .

Table 6. Mean and standard deviation of professionals' Psychological Well-being and its dimensions

\begin{tabular}{lcc}
\hline Psychological well-being $\quad$ and it's dimensions & Mean & Standard Deviation \\
\hline Positive Emotions & 3.15 & 1.27 \\
Positive Relations with Others & 3.33 & 1.26 \\
Meaning \& Purpose in Life & 3.11 & 1.33 \\
Self- Acceptance & 3.22 & 1.21 \\
Environmental Mastery & 3.07 & 1.07 \\
Personal Growth & 2.89 & 1.01 \\
Overall Psychological Well-being & $\mathbf{3 . 1 3}$ & $\mathbf{1 . 0 5}$ \\
\hline
\end{tabular}

\subsection{Results of the Basic Structural Model}

The basic Structural Equation Modelling (SEM) of this study is the relationship between perceived work role demands (PWD), perceived family role demands (PFD) and perceived social role demands (PSD) and Psychological well-being (PWB) with maximum likelihood method. Before analyzing the basic structural model, the skewness and kurtosis of each variable was tested and the results satisfy the conditions for a normal distribution (skewness was less than 2, and kurtosis was less than 4). The $\chi^{2}$ statistic is the basic estimator for evaluation of goodness of fit and it could be made the conclusion that the model is suitable when $\chi^{2}$ statistic is low and the degree of freedom is higher with significance p- value. The following Figure 3 shows the basic structural model of the study and the results for the model fit indices are illustrated in Table 7. 


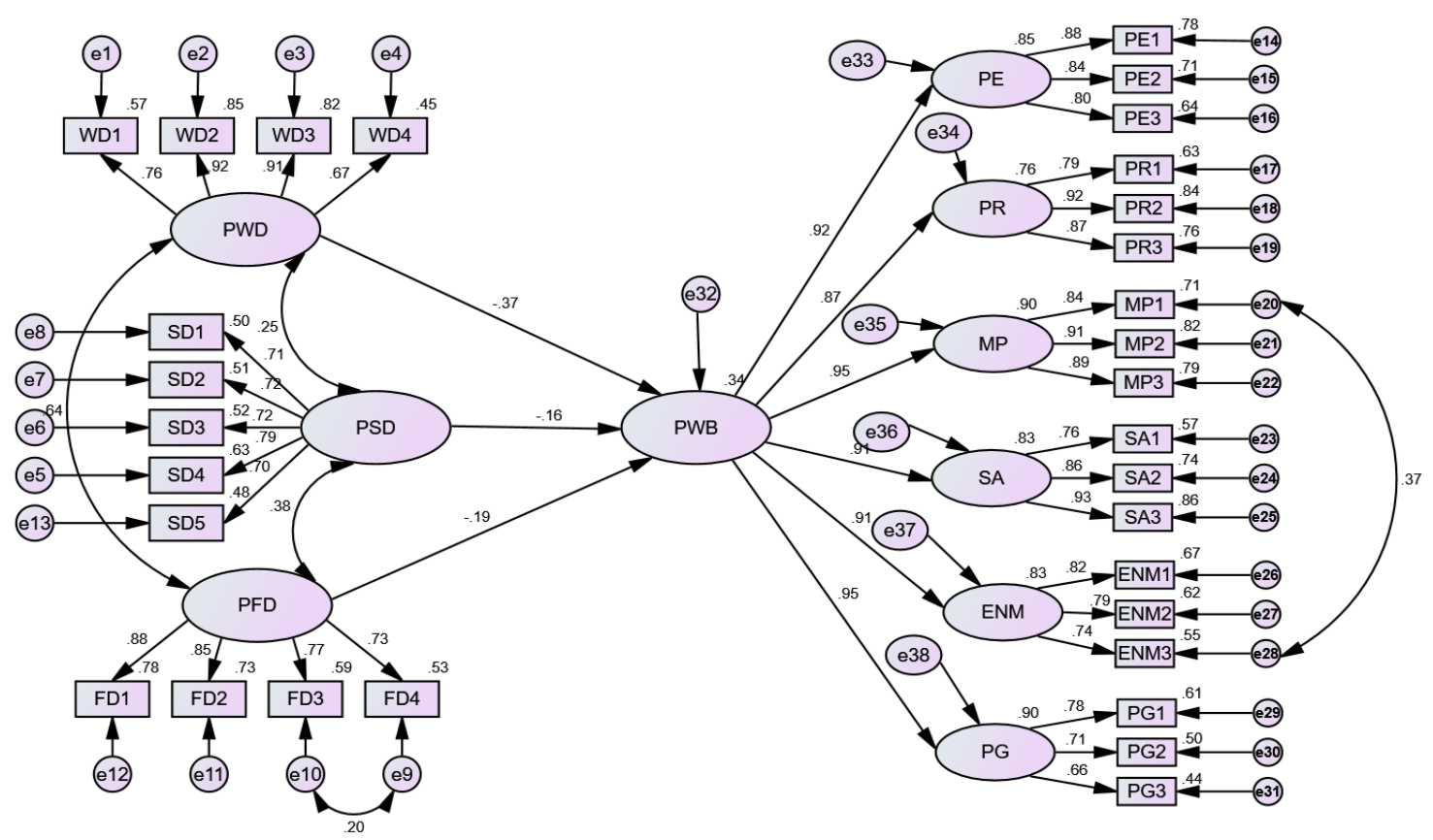

Figure 3. Basic Structural model with significant pathways of focal constructs

\subsection{Results of the Modified Structural Model and Modified Model Fit Indices}

The above basic structural model was modified by using a modification index (24.07) obtained from analysis between MP1 (e20) and PR (e34) by free estimating but some parts were not revised based on the theoretical basis. Besides, all indices of the modified model were better than basic structural model. This shows in Figure 4 . Model fit indices of modified structural model with Threshold values are also shown in Table 7.

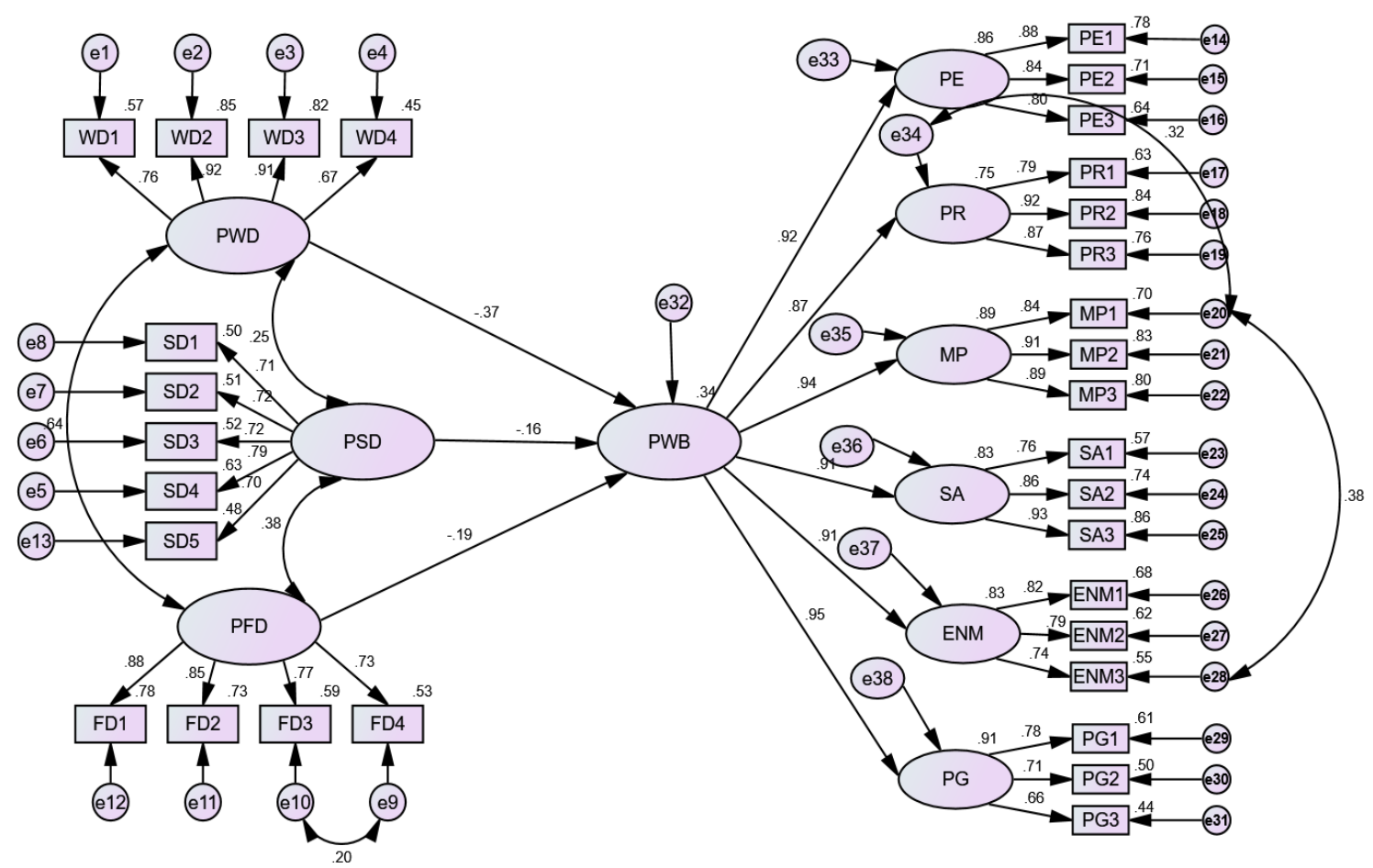

Figure 4. Modified Structural model with significant pathways of focal constructs 
Table 7. Model fit indices of basic structural model, modified structural model and Threshold values

\begin{tabular}{|c|c|c|c|c|c|c|c|c|c|c|c|c|}
\hline \multirow{2}{*}{$\begin{array}{c}\text { Model Fit } \\
\text { Indicators }\end{array}$} & \multicolumn{6}{|c|}{ Absolute Fit Index } & \multicolumn{3}{|c|}{ Incremental Fit Index } & \multicolumn{3}{|c|}{ Parsimonious Fit Index } \\
\hline & $\chi^{2}$ & df & $\chi^{2 / \mathrm{df}}$ & RMSEA & RMR & GFI & TLI & NFI & CFI & AGFI & PNFI & PCFI \\
\hline Basic & 859.11 & 420 & 2.045 & 0.052 & 0.082 & 0.872 & 0.945 & 0.907 & 0.950 & 0.849 & 0.820 & 0.858 \\
\hline Modified & 833.91 & 419 & 1.99 & 0.051 & 0.080 & 0.875 & 0.948 & 0.910 & 0.953 & 0.853 & 0.820 & 0.859 \\
\hline Threshold & Min & Max & 1 & $0.05-0.08$ & $0.05-0.08$ & $\geq 0.9$ & $\geq 0.9$ & $\geq 0.9$ & $\geq 0.9$ & $\geq 0.9$ & Model & \\
\hline Acceptance & Yes & Yes & Yes & Yes & Yes & Yes* & Yes & Yes & Yes & Yes* & Yes & Yes \\
\hline
\end{tabular}

$\mathrm{P}=.000$, (Less than 0.01) \& Threshold values from Zainudeen, (2014). * Approximate value

\subsection{Direct Causal Effects Using Structural Equation Modeling (SEM) and Hypothesis Testing}

Critical Ratio (C.R) is the commonly recommended basis for testing statistical significance of SEM components with C.R values beyond \pm 2.58 establishing significance at $\mathrm{P}<0.01$ level. Standardized $(\beta)$ regression coefficients that indicate the individual direct effect of perceived work role demand (PWD), perceived family role demand (PFD) and perceived social role demand (PSD) on Psychological Well-being (PWB) are shown in Table 8.

Table 8. Standardized $(\beta)$ and Unstandardized (B) Regression Estimates using SEM and Hypothesis testing

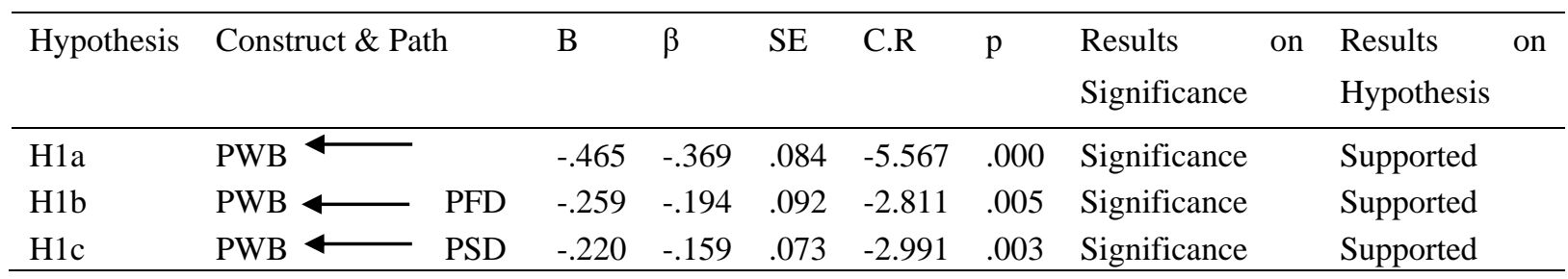

In the above model, perceived work role demands had a significance and negative impact on Psychological Well-being $(\beta=-0.369, p=0.000)$ which indicates that when perceived work role demands increases by one unit, Psychological Well-being decreases by 0.369 units. Similarly perceived family role demands had a significance and negative impact on Psychological Well-being $(\beta=-0.194, p=0.005)$, perceived social role demands had a significance and negative impact on Psychological Well-being $(\beta=-0.159, \mathrm{p}=0.003)$. These results support to the hypotheses of H1a, H1b and H1c.

\subsection{Combined Impacts of Perceived Role Demands on Psychological Well-being and Hypothesis Testing}

To test the degree of combined impacts of perceived role demands on Psychological Well-being, stepwise multiple regression analysis using SPSS 23 has been carried out and the results are presented below in Table 9.

Table 9. Combined impacts of perceived role demands on Psychological Well-being

\begin{tabular}{|c|c|c|c|c|c|c|c|c|c|}
\hline \multirow[b]{2}{*}{ Model } & \multirow[b]{2}{*}{$\mathrm{R}$} & \multirow[b]{2}{*}{ R Square } & \multirow[b]{2}{*}{$\begin{array}{l}\text { Adjusted R } \\
\text { Square }\end{array}$} & \multirow[b]{2}{*}{$\begin{array}{l}\text { Std. Error of the } \\
\text { Estimate }\end{array}$} & \multicolumn{5}{|c|}{ Change Statistics } \\
\hline & & & & & $\begin{array}{l}\text { R Square } \\
\text { Change }\end{array}$ & F Change & df1 & df2 & $\begin{array}{c}\text { Sig. F } \\
\text { Change }\end{array}$ \\
\hline 1 & $.457^{\mathrm{a}}$ & .209 & .207 & .93866 & .209 & 101.463 & 1 & 384 & .000 \\
\hline 2 & $.534^{\mathrm{b}}$ & .285 & .281 & .89357 & .076 & 40.733 & 1 & 383 & .000 \\
\hline 3 & $.559^{\mathrm{c}}$ & .312 & .307 & .87744 & .027 & 15.212 & 1 & 382 & .000 \\
\hline
\end{tabular}

a.Predictors:(Constant), PWD b.Predictors:(Constant), PWD, PFD, c.Predictors:(Constant), PWD, PFD, PSD

According to the results of the above Table 9, it shows that the multiple correlation coefficient (R) of the three predictor variables and PWB was .559 and the R Square was .312 with significant at .000 which is less than 0.05 and $F$ value is 15.212 . It implies that about 31.2 percent of the variance of PWB has been significantly explained 
by the three predictor variables. Therefore, there is statistical evidence to claim that work role demand, family role demands and social role demands jointly and significantly impacts in the degree of PWB. Furthermore, multiple correlation coefficient $(\mathrm{R})$ of the two independent variables of work role demands and family role demands (Model 2) and PWB was .534 and the R Square was .285 with significance at .000 and F value is 40.733. It indicates that about 28.5 percent of the variance of PWB has been significantly explained by the two predictors. These illustrations support to the hypothesis $(\mathrm{H} 1 \mathrm{~d})$ of the degree of combined impacts of work role demands, family role demands and social role demands have jointly and significantly impact on Psychological Well-being.

\subsection{Correlations between Predictors and Criterion Variable and Hypothesis Testing}

The results of correlation study as shown in Table 10, provides that Perceived work role demands was found to be negatively and significantly correlated with Psychological Well-Being $(r=-.457, p=.000)$, Perceived family role demands was found to be negatively and significantly correlated with Psychological Well-Being $(r=-.492$, $\mathrm{p}=.000$ ) and Perceived social role demands was found to be negatively and significantly correlated with Psychological Well-Being ( $r=-.340, \mathrm{p}=.000)$. Besides, the results of hypothesis testing of $\mathrm{H} 2 \mathrm{a}, \mathrm{H} 2 \mathrm{~b}$ and $\mathrm{H} 2 \mathrm{c}$ are presented in Table 11.

Table 10. Correlations (r) between exogenous (predictors) and endogenous (criterion) variables

\begin{tabular}{lcccc}
\hline Variables & PWB & PWD & PFD & PSD \\
\hline 1.PWB & $\mathbf{1 . 0 0 0}$ & & & \\
2.PWD & -.457 & $\mathbf{1 . 0 0 0}$ & & \\
3.PFD & -.492 & .588 & $\mathbf{1 . 0 0 0}$ & \\
4.PSD & -.340 & .210 & .392 & $\mathbf{1 . 0 0 0}$ \\
\hline
\end{tabular}

**. Correlation is significant at the 0.01 level (2-tailed).

Table 11. Hypothesis testing using Correlations

\begin{tabular}{ccccccc}
\hline Hypothesis & \multicolumn{2}{c}{ Correlation \& Path } & $\mathrm{r}$ & $\mathrm{p}$ & Results on Significance & Results on Hypothesis \\
\hline $\mathrm{H} 2 \mathrm{a}$ & $\mathrm{PWB} \longleftrightarrow$ & $\mathrm{PWD}$ & -.457 & .000 & Significance & Supported \\
$\mathrm{H} 2 \mathrm{~b}$ & $\mathrm{PWB} \longleftrightarrow$ & $\mathrm{PFD}$ & -.492 & .000 & Significance & Supported \\
$\mathrm{H} 2 \mathrm{c}$ & $\mathrm{PWB} \longmapsto$ & $\mathrm{PSD}$ & -.340 & .000 & Significance & Supported \\
\hline
\end{tabular}

\subsection{Results of the Moderating Effects of Gender and Hypothesis Testing}

Baron and Kenny (1986) describe a moderator as a factor that influences the direction and/or the strength of the relationship between an exogenous and an endogenous variables. To test the moderating effect of gender using multi group analysis in Amos (Bae, 2011), the original data was split into two groups' namely male (279) and female (107) data sets. To examine the overall moderating effect of gender on the structural model for male group data, the paths of perceived work, family and social role demands to psychological well-being were fully constrained by putting 1 for each paths and it was compared with unconstrained model for the differences between Chi-square $\left(\chi^{2}\right)$ variations (560.865) and degrees of freedom (3). From Chi-square Table, critical value for three degrees of freedom at 0.05 significance level is 7.815 which is less than Chi-square difference (560.865) between constrained and unconstrained model. So moderation occurs in that path. This shows in Table 12.

Further, Bae, (2011) claimed that the variation of $\chi^{2}$ is larger than 3.84 with the change of degree of freedom is one and the result is statistically significant at the $0.05 \%$ level, then moderation occurs in that individual path. To identify the moderation in the individual path of interest, constrained model and unconstraint model using the data set of male were developed. Now the Chi-square difference estimates for both the constrained and unconstrained models were calculated and the results are illustrated in the following Table 13, Table 14 and Table 15 .

The same procedure was repeated for female group data as well. The female group data results for moderation analysis are illustrated in Table 16 given below. 
Table 12. Overall Moderation Test for Male group Data between overall perceived role demands and PWB

\begin{tabular}{|c|c|c|c|c|c|}
\hline Indices & $\begin{array}{l}\text { Constrained } \\
\text { Model }\end{array}$ & $\begin{array}{l}\text { Unconstrained } \\
\text { Model }\end{array}$ & $\begin{array}{l}\text { Chi-Square } \\
\text { Difference }\end{array}$ & $\begin{array}{ll}\text { Results } & \text { on } \\
\text { Moderation } & \\
\end{array}$ & $\begin{array}{l}\text { Results on } \\
\text { Hypothesis }\end{array}$ \\
\hline Chi-Square & 1342.905 & 782.040 & 560.865 & Significance & \\
\hline Degree of Freedom & 422 & 419 & 3 & difference & Supported \\
\hline \multicolumn{5}{|c|}{$\begin{array}{l}\text { Respondent's male group moderates the overall relationship between perceived work, family and social } \\
\text { role demands and Psychological Well-being relationship. }\end{array}$} & Supported \\
\hline
\end{tabular}

Table 13. The Moderation Test for Male group Data between perceived work role demands and Psychological Well- being

\begin{tabular}{llllll}
\hline Indices & $\begin{array}{l}\text { Constrained } \\
\text { Model }\end{array}$ & $\begin{array}{l}\text { Unconstrained } \\
\text { Model }\end{array}$ & $\begin{array}{l}\text { Chi-Square } \\
\text { Difference }\end{array}$ & $\begin{array}{l}\text { Results } \\
\text { Moderation }\end{array}$ & $\begin{array}{l}\text { Results on } \\
\text { Hypothesis }\end{array}$ \\
\hline Chi-Square & 913.957 & 782.04 & 131.917 & Significance & Supported \\
Degree of Freedom & 420 & 419 & 1 & difference & Suppor
\end{tabular}

The hypothesis statement

H3a: Respondent's male group moderates the relationship between perceived work role demands and Supported Psychological Well-being relationship.

Table 14. The Moderation Test for Male group Data between perceived family role demands and Psychological Well- being

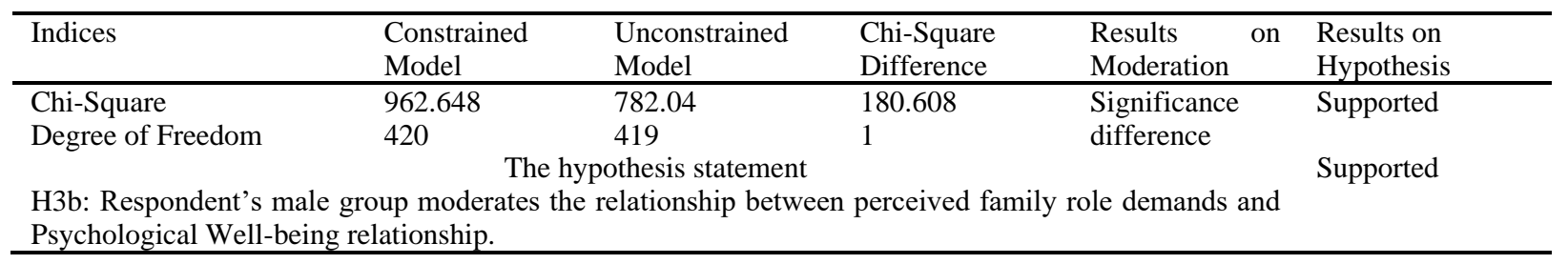

Table 15. The Moderation Test for Male group Data between perceived social role demands and Psychological Well- being

\begin{tabular}{llllll}
\hline Indices & $\begin{array}{l}\text { Constrained } \\
\text { Model }\end{array}$ & $\begin{array}{l}\text { Unconstrained } \\
\text { Model }\end{array}$ & $\begin{array}{l}\text { Chi-Square } \\
\text { Difference }\end{array}$ & $\begin{array}{l}\text { Results } \\
\text { Moderation }\end{array}$ & $\begin{array}{l}\text { Results on } \\
\text { Hypothesis }\end{array}$ \\
\hline Chi-Square & 874.848 & 782.04 & 92.808 & Significance & Supported \\
Degree of Freedom & 420 & $\begin{array}{l}419 \\
\text { difference }\end{array}$ & Supported
\end{tabular}

H3c: Respondent's male group moderates the relationship between perceived social role demands and Psychological Well-being relationship.

Table 16. Results of moderating effects of Female data using multi group CFA analysis in Amos 21

\begin{tabular}{|c|c|c|c|c|c|}
\hline $\begin{array}{l}\text { Independent } \\
\text { Variable }\end{array}$ & $\begin{array}{l}\text { Dependent } \\
\text { Variable }\end{array}$ & $\begin{array}{l}\text { Gender } \\
\text { Group }\end{array}$ & $\begin{array}{l}\text { Constrained Model } \chi^{2} \\
(\text { d.f. }=420)\end{array}$ & $\begin{array}{l}\text { Unconstrained Model } \\
\chi 2(\text { d.f. }=419)\end{array}$ & $\Delta \chi 2($ d.f. $=1)$ \\
\hline PWD & \multirow[t]{3}{*}{ PWB } & Female & 710.900 & 652.826 & 58.074 \\
\hline PFD & & Female & 720.430 & 652.826 & 67.604 \\
\hline PSD & & Female & 715.518 & 652.826 & 62.692 \\
\hline
\end{tabular}

From the above illustrations, the results revealed that moderation is significant for male group between perceived work, family and social role demands and Psychological Well-being relationship since the difference in ChiSquare value between constrained and unconstrained model is more than 3.84 for all three cases for one degree of freedom. As seen from Table 16, the moderation of female group between perceived work, family and social role demands and psychological well-being relationship is also significant since the difference in Chi Square value between constrained and unconstrained model is more than 3.84 for all three cases with one degree of freedom. These also support the hypotheses of H3a, H3b and H3c. Since both male group and female group moderation estimates are significant partial moderation occurs (Bae, 2011). 


\section{Discussions}

The results of this study findings show that the overall mean level of psychological well-being was 3.13 with a standard deviation of 1.05 which is in the moderate category. Considering the overall level of psychological well-being, the findings revealed that mean value was in the moderate category $(\mathrm{M}=3.01, \mathrm{SD}=0.80)$. It was identified from the analysis that $36.53 \%$ of the respondents (141) perceive low level of psychological well-being whereas $19.43 \%$ of the respondents (75) perceive moderate level of psychological well-being and $44.04 \%$ of the respondents (170) perceive high level of psychological well-being. It implies that there is room for redress the poor psychological well-being among professionals. It is important to note that all dimensions of the Psychological well-being also yield into moderate category. Besides, male professionals perceived higher overall psychological well-being (3.18) than that of their counterpart female professionals (2.99). According to the findings of Ryff (1995), there were significant gender differences in psychological well-being which was supported by the current study. Furthermore, this research finding is consistent with the results of Khanbani et al. (2014) who report that there was significant differences between men and women in some of the aspects of psychological well-being and

Adelmann (1994a) study who has shown that better health to be stronger for men than for women.

The results for the modified structural model indicates the Goodness of Fit Index (GFI) was 0.875, Normed Fit Index (NFI) was 0.910 showing an overall good fit of the model. Similarly, the root mean square error of approximation (RMSEA) yields a good fit of 0.051 and Root Mean Square Residual (RMR) is 0.08. Comparative Fit Index (CFI) was 0.953 and Tucker- Lewis Index (TLI) was 0.948 and CMIN/DF value of 1.99 which is within the threshold value of less than 3.0. These shows that the model fits the data in an acceptable way within the threshold values.

Furthermore this study provides that Perceived work demands was found to be negatively and significantly correlated with Psychological Well-Being ( $\mathrm{r}=-.457, \mathrm{p}=.000$ ), Perceived family demands was found to be negatively and significantly correlated with Psychological Well-Being $(\mathrm{r}=-.492, \mathrm{p}=.000)$, Perceived social demands was found to be negatively and significantly correlated with Psychological Well-Being $(r=-.340$, $\mathrm{p}=.000$ ). In the above modified structural model, perceived work role demands had a negative impact on Psychological Well-being $(\beta=-0.369, \mathrm{p}=0.000)$. Similarly perceived family role demands had a negative impact on Psychological Well-being $(\beta=-0.194, p=0.005)$, perceived social role demands had a negative impacts on Psychological Well-being $(\beta=-0.159, \mathrm{p}=0.003)$. Thus, the strength of the relationship is in the order of highest for work demands then family demands and least strength to social demands.

The findings of the study shows that the hypotheses which states that Perceived role demands have a significant negative impact on Professionals Psychological Well-being has been supported. This research finding is consistent with the results of Thompson (2006) who claimed that role over load or heavy job demands lead to work pressure that affect employees physical health as well as psychological well-being. According to MultiGroup CFA, the estimates for both the constrained and unconstrained model, Chi-Square value differs by more than 3.84 so that the moderation occurs in that individual path in such a way that gender has a moderating effect between perceived role demands and psychological well-being relationships with partial moderation. Thus the hypothesis that Gender has a moderating effect on the relationship between work, family and social role demands and Psychological Well-being relationship were supported.

\section{Conclusions}

The analysis shows that professionals involved in this study possess an average level of psychological well-being but there are rooms for further improvements of their psychological well-being aspects. The findings also indicated an average score category of all the dimensions of Positive Emotions, Positive Relations with Others, Meaning \& Purpose in Life, Self- acceptance, Environmental Mastery and Personal Growth. Finding also shows that male professionals have higher psychological well-being than that of their counter part of female professionals. The overall results for the model fit indices revealed that the data fit the model in a good manner. This study provides some important insights that the negative and significance correlations between perceived work, family and social demands on psychological well-being has been established. The strength of the relationship is higher for work demands than family demands and least for social demands. Besides, perceived work, family and social demands have negative and significant impacts on psychological well-being and combined impacts is also significant. Furthermore, more precisely, this study has shown that gender has a moderating effect between perceived role demands and psychological well-being relationships with partial moderation. 


\section{Implications, Limitations and Directions for Future Research}

\subsection{Managerial and Social Implications}

This study is significance to professionals, employees, family members, human resource managers, medical practitioners, psychologist, policy makers and researchers as it is crucial that they must address the needs of employees regarding psychological well-being issues. Understanding how different role demands influence psychological well-being will help to provide a context in which professional live and a background for understanding of their current status of psychological well-being. Organizational leaders and policy makers should apply creative thinking to develop strategies and policies to combat or address the psychological well-being issues in an effective and efficient way. Furthermore, it would help organizations to devise ways of dealing with employee absence or declining productivity due to poor psychological well-being. Social implication is important as work, family and social domains are most important and inter-connected to most people and performing of multiple role impacts their individuals' life significantly. Therefore, it is recommends the public organizations to think and act in terms of policy and practice aspects to improve the psychological well-being of professionals. Hence, the study would have policy and implementation implications for public service organizations.

\subsection{Limitations and Directions for Future Research}

The first and foremost limitations of the study is that all of the measures were self-reported that common method bias may influence the study. Another limitation is that the research design is cross sectional survey and it would not depict the true causality. Hence, further studies using longitudinal design would be useful in establishing the temporal order of relationship and insights of strong causal relationships among variables. Since the focal point of this study is public sector, future study also could be conducted among the private sector professionals in Sri Lanka.

\section{References}

Adelmann, P. K. (1994a). Multiple roles and physical health among older adults. Research on Aging, 16, 42-167. https://doi.org/10.1177/0164027594162002

Bae, B. (2011). Structural Equation Modeling with AMOS 19: Principles and Practice. Cheongram Book: Seoul, Korea.

Baron, R. M., \& Kenny, D. A. (1986). The moderator-mediator variable distinction in social psychological research: conceptual, strategic, and statistical considerations. Journal of personality and social psychology, 51(6), 1173-1182. https://doi.org/10.1037/0022-3514.51.6.1173

Boyar, S. L., Carr, J. C., Mosley, D. C. J., \& Carson, C. M. (2007). The development and validation of scores on perceived work and family demand scales. Educational and Psychological Measurement, 67, 100-15. https://doi.org/10.1177/0013164406288173

Bradburn, N. M. (1969). The structure of psychological well-being. Chicago, IL: Aldine. https://doi.org/10.1037/t10756-000

Deci, E. L., \& Ryan, R. M. (2008). Hedonia, Eudaimonia, and well-being: An introduction. Journal of Happiness Studies, 9, 1-11. https://doi.org/10.1007/s10902-006-9018-1

Demerouti, E., Bakker, A. B., \& Nachreiner, F. (2001). The job demands-resources model of burnout. Journal of Applied Psychology, 86(3), 499-512. https://doi.org/10.1037/0021-9010.86.3.499

Edwards, S. D. (2005). A psychology of breathing methods. International Journal of Mental Health Promotion, 7(4), 28-34. https://doi.org/10.1080/14623730.2005.9721958

Field, A. (2009). Discovering Statistics using SPSS $3^{\text {rd }}$ Edition. SAGE Publications Inc.

Fornell, C., \& Larcker, D. F. (1981). Evaluating structural equation models with unobservable variables and measurement error. Journal of Marketing Research, 18(1), 39-50. https://doi.org/10.1177/002224378101800104

Gechman, A., \& Wiener, Y. (1975). Job involvement and satisfaction as related to mental health and personal time devoted to work. Journal of Applied Psychology, 60, 521-523. https://doi.org/10.1037/h0076902

Goode, W. J. (1960). A theory of role strain. American Sociological Review, 25, 483-496. https://doi.org/10.2307/2092933

Hair, J. F., Black, W. C., Babin, B. J., \&Anderson, R. E. (2014). Multivariate data analysis (7th ed.). Prentice 
Hall, Englewood Cliffs.

Helson, S., \& Srivastava, S. (2001). Three paths of adult development: conservers, seekers, and achievers. Journal of Personality and Social Psychology, 80, 995-1010. https://doi.org/10.1037/0022-3514.80.6.995

Huppert, F. A. (2009). Psychological well-being: Evidence regarding its causes and consequences. Applied Psychology: Health and Well-Being, 1, 137-164. https://doi.org/10.1111/j.1758-0854.2009.01008.x

Khanbani, M., Asghar, A., \& Gol Parvar., M. (2014).Examining the Relationship between Gender and Psychological Well- Being. Journal of Sociological Research, 5(1). https://doi.org/10.5296/jsr.v5i1.5436

Lyness, K. S., \& Thompson, D. E. (2000). Climbing the corporate ladder: do female and male executives follow the same route? Journal of Applied Psychology, 85(1). https://doi.org/10.1037/0021-9010.85.1.86

Marks, S. R. (1977). Multiple roles and role strain: Some notes on human energy, time, and commitment. American Sociological Review, 42, 921-936. https://doi.org/10.2307/2094577

Ministry of Health, Nutrition \& Indigenous Medicine, Sri Lanka (2017). Weekly Epidemiological Report, 44(15).

Nunnally, J. C. (1978). Psychometric theory (2nd ed.). New York: McGraw - Hill.

Parasuraman, S., Greenhaus, J. H., \& Granrose, C. S. (1992). Role stressors, social support, and well-being among two-career couples. Journal of Organizational Behavior, 13, 339-356. https://doi.org/10.1002/job.4030130403

Register General, Sri Lanka (2019). Suicide mortality rate in Sri Lanka for year 2018, Register General's office, Colombo, Sri Lanka.

Robertson, T., Cooper, R., \& Cooper, L. (2010). Full engagement: the integration of employee engagement and psychological well-being. Leadership \& Organization Development Journal, 31(4). https://doi.org/10.1108/01437731011043348

Roothman, B., Kirsten, D., \& Wissing, M. (2003). Gender differences in aspects of psychological well-being. South African Journal of Psychology, 33(4), 212-218. https://doi.org/10.1177/008124630303300403

Ryan, R. M., \& Deci, E. L. (2001). On happiness and human potentials: A review of research on hedonic and eudaimonic well-being. Annual Review of Psychology, 52, 141-166. https://doi.org/10.1146/annurev.psych.52.1.141

Ryff, C. D. (1989). Happiness is everything, or is it? Explorations on the meaning of eudaimonic well-being. Journal of Personality and Social Psychology, 57, 1069-1081. https://doi.org/10.1037/0022-3514.57.6.1069

Ryff, C. D. (1995). Psychological well-being in adult life. Current Directions in Psychological Science, 4(4), 99-104. https://doi.org/10.1111/1467-8721.ep10772395

Ryff, C. D. (2017). Eudaimonic well-being, inequality and health: recent findings and future directions. International Reviews of economics, 64(2), 159-178. https://doi.org/10.1007/s12232-017-0277-4

Ryff, C. D., \& Singer, B. (1998). The contours of positive human health. Psychological Inquiry, 9, 1-28. https://doi.org/10.1207/s15327965pli0901_1

Sekaran, U. (1985).The paths to mental health: an exploring study of husbands and wives in dual career families. Journal of occupational Psychology, 58, 129-137. https://doi.org/10.1111/j.2044-8325.1985.tb00188.x

Sekaran,U.(2003).Research Methods for Business, A Skill Building Approach (4th ed.). John Wiley \& Sons, United Kingdom.

Stamp, E., Crust, L., Swann, C., Perry, J., Clough, P., \& Marchant, D. (2015). Relationships between Mental Toughness and Psychological Wellbeing in Undergraduate Students. Personality and Individual Differences, 75, 170-174. https://doi.org/10.1016/j.paid.2014.11.038

Udhayakumar, P., \& Illango, P. (2018). Psychological Wellbeing among College Students. Journal of Social Work Education and Practice, 3(2), 79-89.

Voydanoff, P. (2004a). The effects of work demands and resources on work-to-family conflict and facilitation. Journal of Marriage and Family, 66, 398-412. https://doi.org/10.1111/j.1741-3737.2004.00028.x

Voydanoff, P. (2004b). The effects of work and community resources and demands on family integration. Journal of Family and Economic Issues, 25, 7-23. https://doi.org/10.1023/B:JEEI.0000016721.71785.06

World health Organization (2014). Mental health: A state of well-being. Retrieved from www.who.int/features/factfiles/mental_health/en 
World Health Organization. (2019). What is Mental Health? Retrieved from http://www.who.int/features/qa/62/en

World Health Organization. (2011a). Mental health atlas 2011. Sri Lanka.

World Health Organization. (2011b). World report on disability, Geneva.

Wright, T. A., Cropanzano, R., \& Bonett, D. G. (2007). The moderating role of employee positive well-being on the relation between job satisfaction and job performance. Journal of Occupational Health Psychology, 12(2), 93-104. https://doi.org/10.1037/1076-8998.12.2.93

Zainudeen, W. (2014). Analyzing the effect of a moderator in model: The Multi - Group CFA procedure in SEM. University of Sultan, Malaysia.

\section{Copyrights}

Copyright for this article is retained by the author(s), with first publication rights granted to the journal.

This is an open-access article distributed under the terms and conditions of the Creative Commons Attribution license (http://creativecommons.org/licenses/by/4.0/). 